\title{
Assessment of damage to buildings and farms during the $2011 M 9.0$ earthquake and tsunami in Japan from remote sensing data
}

\author{
GUO HuaDong ${ }^{*}$, CHEN Yu*, FENG Qiang, LIN QiZhong \& WANG Fei \\ Center for Earth Observation and Digital Earth, Chinese Academy of Sciences, Beijing 100094, China
}

Received March 21, 2011; accepted April 15, 2011

\begin{abstract}
At 13:46 on March 11, 2011 (Beijing time), a great earthquake of magnitude of 9.0 occurred off the Pacific coast of northeastern Japan (Tohoku Region). After the earthquake, the Center for Earth Observation and Digital Earth (CEODE), Chinese Academy of Sciences, quickly launched a major disaster emergency response to assess the disaster. In this paper, we have extracted buildings and farms in the heavily devastated area that includes Iwate, Miyagi, and Fukushima Prefectures, based on multi-spectral remote sensing data. We have assessed building damage by overlaying seismic intensity and building distributions. In addition, we have assessed the extent of building and farm damage caused by the tsunami through the establishment of a tsunami impact assessment model that is based on terrain and distance from the coastline. The results were partially verified by high-resolution images obtained after the disaster. The results show that about $76 \%$ of buildings in Miyagi Prefecture were affected by seismic intensity 6 and above, with $24 \%$ of the buildings and $12 \%$ of the farms destroyed by the tsunami. These huge losses were echoes at lesser amounts in Fukushima and Iwate. The results provide the support of basic data, which can be further developed by economic and social aspects of the disaster assessment.
\end{abstract}

Japan, earthquake, tsunami, disaster emergency response, disaster assessment

Citation: Guo H D, Chen Y, Feng Q, et al. Assessment of damage to buildings and farms during the 2011 M9.0 earthquake and tsunami in Japan from remote sensing data. Chinese Sci Bull, 2011, 56: 2138-2144, doi: 10.1007/s11434-011-4544-6

At 13:46 on March 11, 2011 (Beijing time), a great earthquake of magnitude 9.0 (http://earthquake.usgs.gov/earthquakes/eqinthenews/2011/usc0001xgp/) occurred with an epicenter located $130 \mathrm{~km}$ off the Pacific coast of the northeastern part of the Japanese island of Honshu (Tohoku Region). The earthquake and subsequent tsunami caused a huge loss of life and property. According to the Japanese National Police Agency, 11438 people had died and 16493 people were missing as of 6:00 pm on March 30, 2011. The damage to buildings and farms caused by the earthquake and tsunami is one of the key evaluation indices for its close relationship to post-disaster reconstruction and food security. Remote sensing satellite TM/ETM images at moderate spatial resolution have been widely used in land cover classification, especially at a county-level scale $[1,2]$. We charac-

*Corresponding authors (email: hdguo@ceode.ac.cn; yuchen@ceode.ac.cn) terized the buildings and farms in heavily devastated areas including Iwate, Miyagi, and Fukushima Prefectures, based on multi-spectral remote sensing data. We assessed the building damage by overlaying seismic intensity (http:// www.seisvol.kishou.go.jp/eq/suikei/201103111446_288/20 1103111446_288_1.html) and building distributions. In addition, we established a tsunami impact assessment model based on the terrain and the distance from the coastline. The results were partially verified by high-resolution images obtained after the disaster.

\section{Extraction of buildings and farms}

Figure 1 shows an ETM (7/4/3) composite image of the disaster area, which was stitched from three images. The path and row numbers of the three images are 107/32, $107 / 33$, and $107 / 34$. The first two images were obtained on 


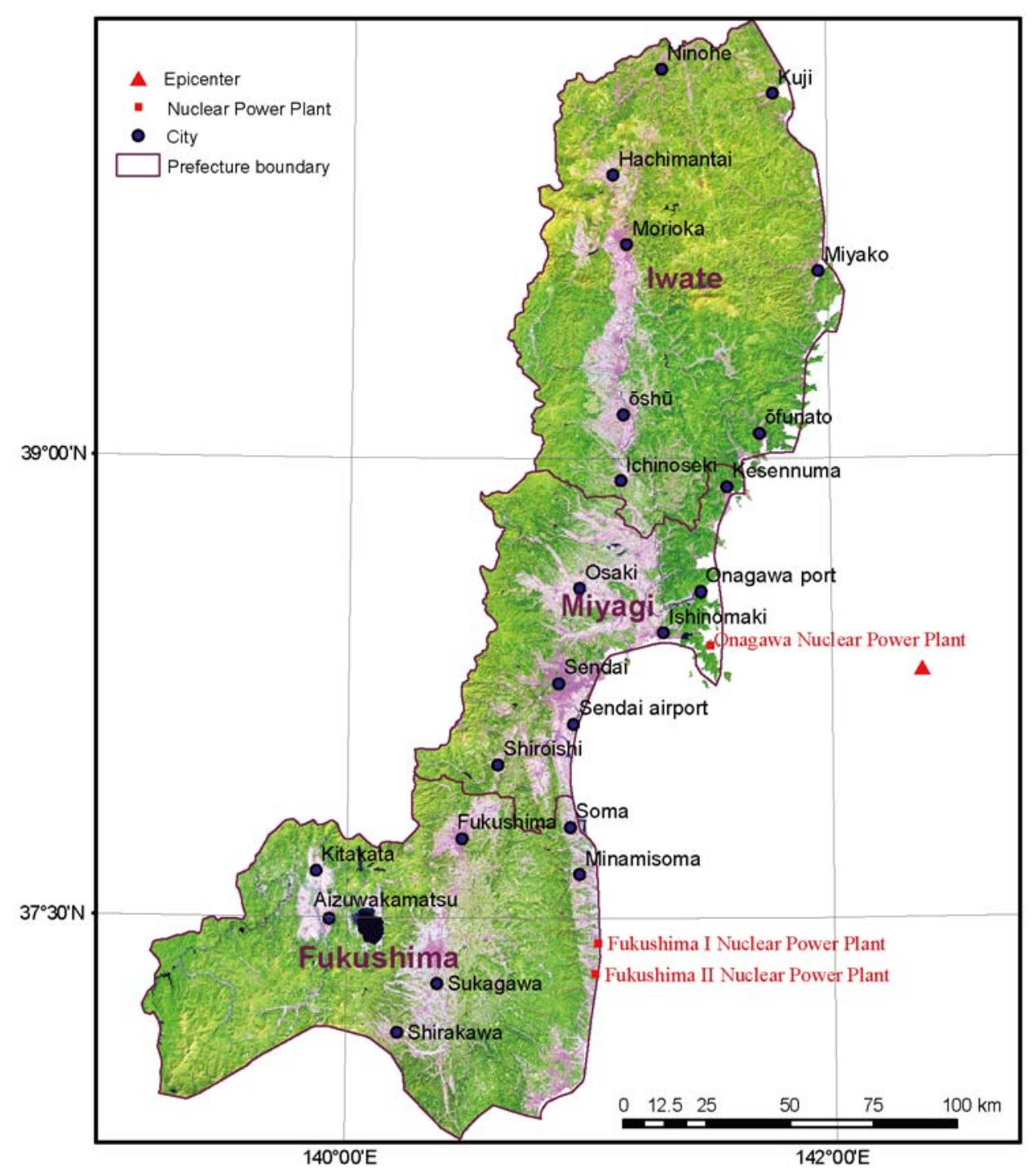

Figure 1 ETM (7/4/3) composite image of most damaged region.

September 21, 2000, and the third on September 24, 2000. As the urbanization of Japan had been completed by the 1970s, urban growth and land use change since 2000 are not significant, which can be confirmed by analyzing change in Google Earth images of Sendai, Osaki, Minamisoma and other areas. Figure 2(a), (b), and (c) shows the land use condition in an urban fringe zone of Sendai since 2000 (with a central latitude and longitude of $140^{\circ} 56^{\prime} 42^{\prime \prime} \mathrm{E}, 38^{\circ} 13^{\prime} 27^{\prime \prime} \mathrm{N}$ ). We could find no obvious changes in building distribution and land use. In addition, the spectral characteristics of farms in late September are quite different from those of mountain vegetation. The use of images obtained at this time helps to improve the accuracy of the extracted results.

The extraction of buildings and farms from satellite imagery, which is based on a parallelepiped method, is summarized in Figure 3. For this purpose, buildings include houses, roads, and engineering facilities whereas farms include agricultural land and seasonal crops, which are locat- ed in relatively flat areas; forests and fruit trees, which are located on hilly terrain, are not included. The results were partially verified by high-resolution images that were obtained after the disaster (Figure 2(d)). A statistical summary of buildings and farms in the disaster area is shown in Table 1.

\section{Assessment of buildings damaged by earthquake}

The picture in the top-left corner of Figure 3 shows the spatial distribution of seismic intensities during the earthquake, as released by the Japan Meteorological Agency (JMA) [3]. Seismic intensity 7 is the highest degree of intensity on the Japanese scale, which corresponds to seismic intensity 11 or above on the scale used in China (http://www.csi.ac.cn/ $\mathrm{ymd} / \mathrm{flfg} / \mathrm{fd} 007 . \mathrm{htm})$. The energy released in this earthquake was great. However, the epicenter was $130 \mathrm{~km}$ off the 

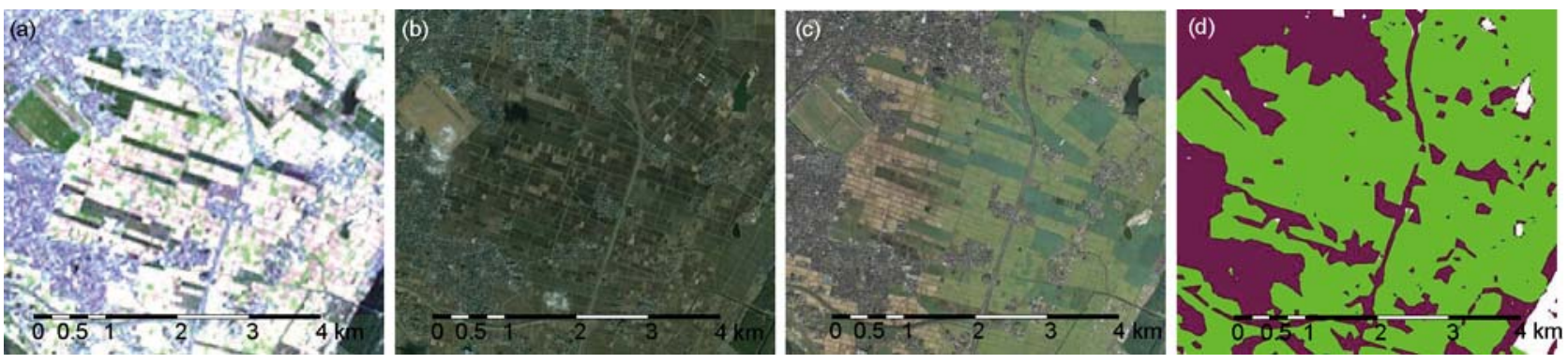

Figure 2 The land use change and results of information extraction from suburban Sendai. (a) ETM image obtained on September 21, 2000; (b) highresolution image obtained on December 26, 2001; (c) high-resolution image obtained on August 26, 2008; (d) differentiation between buildings (purple heart) and farms (green) based on ETM images.

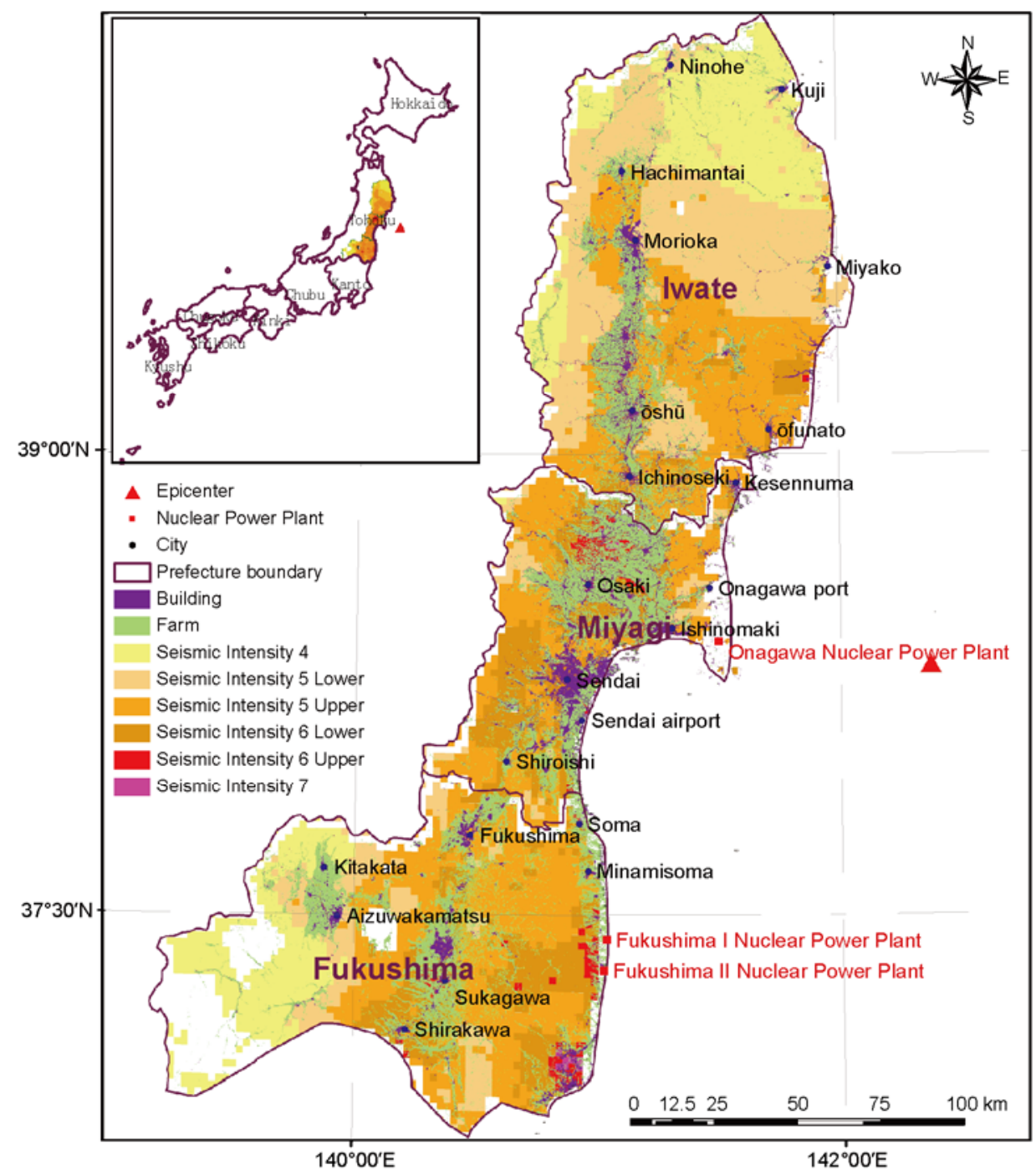

Figure 3 Overlay analysis of seismic intensity and buildings and farms within areas of greatest damage.

Table 1 Areal coverage of buildings and farms

\begin{tabular}{lcc}
\hline & Buildings $\left(\mathrm{km}^{2}\right)$ & Farms $\left(\mathrm{km}^{2}\right)$ \\
\hline Iwate & 590.771 & 1818.357 \\
Miyagi & 713.611 & 1873.449 \\
Fukushima & 354.006 & 2248.504 \\
Total & 1658.388 & 5940.31 \\
\hline
\end{tabular}

Pacific coast of the northeastern part of the Japanese mainland (Tohoku Region of Honshu). The southeast region of Fukushima and northern parts of Miyagi Prefectures suffered the highest seismic intensity. A wider region experienced seismic intensity 6 or 5 . Western parts of Iwate and northern parts of Fukushima Prefectures experienced 
seismic intensity 4 or below. By overlaying distributions of buildings and the seismic intensity, the JMA seismic intensity statistics of buildings can be seen (Table 2). According to Japanese intensity level descriptions [3], house collapses exceeding $30 \%$ (construction quality in Japan is high), landslides, ground cracking, and faulting occur at seismic intensity 7. Seismic intensity 6 corresponds to less than $30 \%$ house collapse, landslides, ground cracking, and the inability of most people to stand. Walls crack, gravestones and stone lanterns collapse, and chimneys are damaged by seismic intensity 5 . As can be seen from the statistical results, $76 \%$ of buildings in Miyagi Prefecture suffered seismic intensity 6 or above; this was the most seriously damaged area of the earthquake, followed by Fukushima.

\section{Simulation of tsunami damage}

Another significant feature of the earthquake is that the losses caused by the tsunami are heavy. A British researcher considered that the waves of the tsunami triggered by the earthquake were as high as $10 \mathrm{~m}$, penetrated several $\mathrm{km}$ inland, and may be considered " case of the millennium" in terms of scale (http://www.bbc.co.uk/news/science-environment-12740649). Media reported that the tsunami penetrated as much as $10 \mathrm{~km}$ inland. The impact of the tsunami on infrastructure and farms is influenced by terrain, distance from the coastline, surface roughness and other factors. We assessed the loss of buildings and farms damaged by the tsunami through the establishment of a tsunami impact assessment model, which is based on terrain and distance from the coastline. The model can be formulated as

$$
F=f(H+k \cdot D),
$$

where $H$ is the altitude difference between the evaluation point and sea level. The research is based on Global Digital Elevation Model (GDEM) data, which were provided by Japanese Economy and Industry (METI) and NASA. The relative height accuracy in the model can reach several meters, which fully meets the analytical needs. Parameter $D$ in the formula represents the distance from the coastline. Parameter $k$ represents the attenuation coefficient, which can be determined as the value of the reduced wave height when the tsunami advanced $1 \mathrm{~m}$ over the ground. Parameter $k$ is affected by surface roughness characteristics of the tsunami itself and other factors. Considering some observations and related media information (e.g. the tsunami wave height reaching $10 \mathrm{~m}$ and the tsunami invading a few $\mathrm{km}$ inland), we set the value of $k$ to $1 / 200$. The value of $(H+k \cdot D)$ represents an evaluation that is based on the comprehensive consideration of terrain features and the distance from the coastline. The function $f$, through a certain transformation, can quantify the degree of impact by the tsunami. In this paper, we used a segmentation approach, by which the most heavily damaged areas were partitioned into areas of highly serious impact, serious impact, general impact, and no effect. The partition elevations were set at $10 \mathrm{~m}$ (equivalent to the maximum tsunami wave height), $30 \mathrm{~m}$ (the relative height difference that can be affected by the tsunami), $100 \mathrm{~m}$ (the relative height difference of the region buffering the affected zone) for the value of $(H+k \cdot D)$. Figure 4 shows the tsunami impact partitions for each degree.

We chose high-resolution remote sensing images of the Sendai region for a partial validation of the proposed tsunami impact divisions. As Figure 5(a) shows, the Arahama region of Sendai City is located in the highly serious impact area (red). Figure 5(d) shows the area before the tsunami and Figure 5(e) shows the area afterward. We can readily see that this area suffered devastating damage. The Sendai airport is located in the serious impact area (yellow). As Figure 5(b) and (c) shows, the tsunami flooded the runway and most buildings at the airport. Some residents in the area had to run to high land for refuge. Areas A, B, and C in Figure 5(a) are located in the general impact area (green). They lie mainly within a buffer zone that includes the upstream regions of rivers affected by the tsunami. Parts of these areas suffered tsunami invasion. Area D covers the urban center and the eastern part of Sendai. This region did not experience direct tsunami invasion. Tables 3 and 4 summarize the impact of the tsunami on infrastructure and farms, respectively, based on the overlay analysis. The statistical results show that damage to both infrastructure and farms in Miyagi Prefecture is serious.

After comprehensive analysis of the damage caused by earthquake and tsunami, we find that Miyagi suffered the heaviest losses in this earthquake, followed by Fukushima.

Table 2 JMA Seismic Intensity statistics for buildings in three prefectures

\begin{tabular}{|c|c|c|c|c|c|c|}
\hline \multirow{2}{*}{$\begin{array}{l}\text { JMA seismic } \\
\text { intensity }\end{array}$} & \multicolumn{2}{|c|}{ Buildings of Iwate } & \multicolumn{2}{|c|}{ Buildings of Miyagi } & \multicolumn{2}{|c|}{ Buildings of Fukushima } \\
\hline & Area $\left(\mathrm{km}^{2}\right)$ & Proportion (\%) & Area $\left(\mathrm{km}^{2}\right)$ & Proportion (\%) & Area $\left(\mathrm{km}^{2}\right)$ & Proportion (\%) \\
\hline 4 and Below & 30.976 & 5.243 & 0.006 & 0.001 & 9.564 & 2.702 \\
\hline 5 Lower & 93.298 & 15.793 & 18.918 & 2.651 & 31.207 & 8.815 \\
\hline 5 Upper & 392.848 & 66.497 & 149.793 & 20.991 & 114.084 & 32.227 \\
\hline 6 Lower & 73.212 & 12.393 & 424.100 & 59.430 & 136.715 & 38.619 \\
\hline 6 Upper & 0.437 & 0.074 & 118.182 & 16.561 & 51.012 & 14.410 \\
\hline Total & 590.771 & 100.000 & 713.611 & 100.000 & 354.006 & 100.000 \\
\hline
\end{tabular}




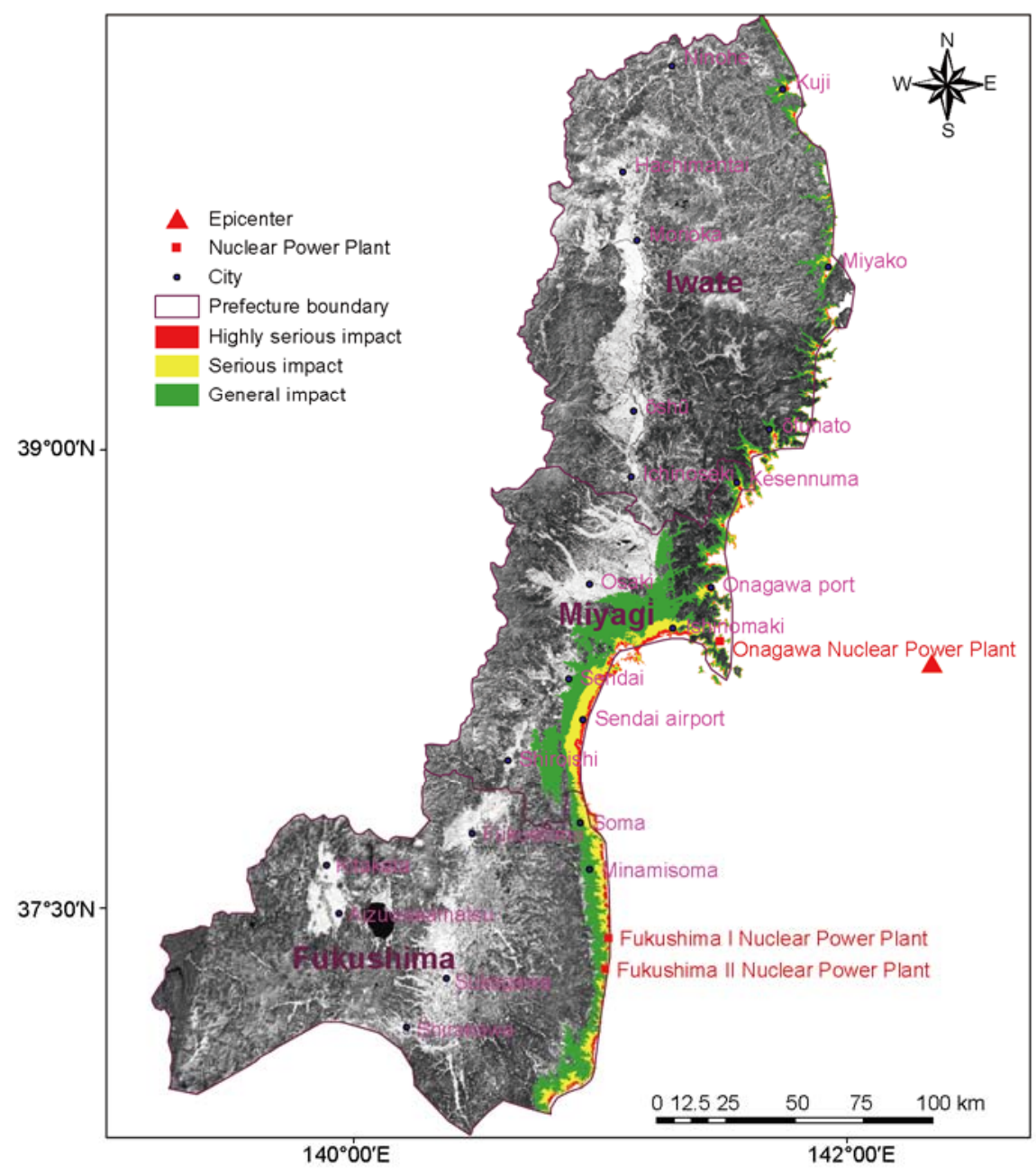

Figure 4 Tsunami impact partitions along the most highly affected part of the coast of Honshu.

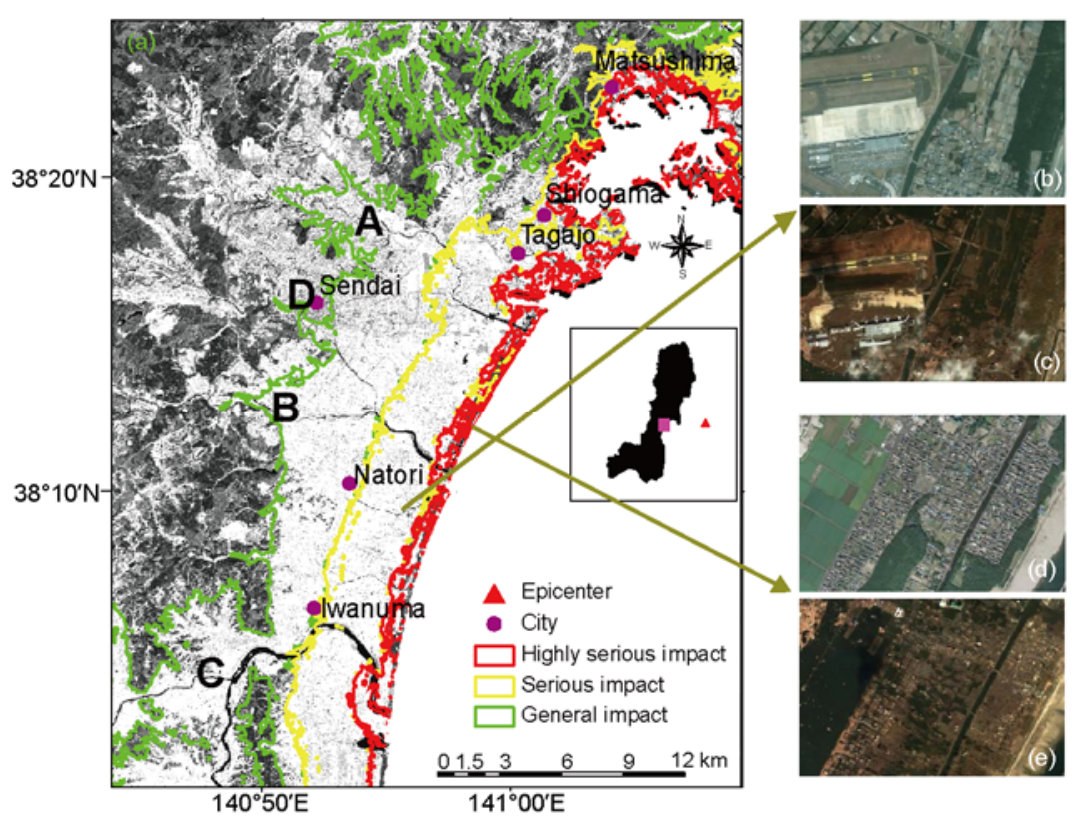

Figure 5 (a) Partial validation of the credibility of the division result of the tsunami's impact. The high-resolution remote sensing images are from Google. (b) Sendai airport before earthquake; (c) Sendai airport after earthquake; (d) Arahama in Sendai before earthquke; (e) Arahama in Sendai after earthquake. 
Table 3 Tsunami damage statistics for buildings in three prefectures

\begin{tabular}{|c|c|c|c|c|c|c|}
\hline \multirow{2}{*}{ Tsunami damage } & \multicolumn{2}{|c|}{ Buildings of Iwate } & \multicolumn{2}{|c|}{ Buildings of Miyagi } & \multicolumn{2}{|c|}{ Buildings of Fukushima } \\
\hline & Area $\left(\mathrm{km}^{2}\right)$ & Proportion (\%) & Area $\left(\mathrm{km}^{2}\right)$ & Proportion (\%) & Area $\left(\mathrm{km}^{2}\right)$ & Proportion (\%) \\
\hline Highly serious & 16.389 & 2.772 & 56.088 & 7.860 & 16.724 & 4.724 \\
\hline Serious & 41.139 & 6.958 & 116.146 & 16.276 & 37.217 & 10.513 \\
\hline General & 33.600 & 5.683 & 233.350 & 32.700 & 51.213 & 14.467 \\
\hline Total & 91.128 & 15.413 & 405.584 & 56.836 & 105.154 & 29.704 \\
\hline
\end{tabular}

Table 4 Tsunami damage statistics for farms

\begin{tabular}{|c|c|c|c|c|c|c|}
\hline \multirow{2}{*}{ Tsunami damage } & \multicolumn{2}{|c|}{ Farms of Iwate } & \multicolumn{2}{|c|}{ Farms of Miyagi } & \multicolumn{2}{|c|}{ Farms of Fukushima } \\
\hline & Area $\left(\mathrm{km}^{2}\right)$ & Proportion (\%) & Area $\left(\mathrm{km}^{2}\right)$ & Proportion (\%) & Area $\left(\mathrm{km}^{2}\right)$ & Proportion (\%) \\
\hline Highly serious & 4.542 & 0.250 & 36.853 & 1.967 & 35.105 & 1.561 \\
\hline Serious & 22.564 & 1.241 & 180.542 & 9.637 & 135.692 & 6.035 \\
\hline General & 37.509 & 2.063 & 557.290 & 29.747 & 223.037 & 9.919 \\
\hline Total & 64.615 & 3.554 & 774.685 & 41.351 & 393.834 & 17.515 \\
\hline
\end{tabular}

In Miyagi, nearly $76 \%$ of the buildings experienced ground shaking with a seismic intensity of 6 and above (on the Japanese intensity scale). $24 \%$ of the buildings and $12 \%$ of the agricultural land suffered from tsunami invasion. In addition to the regional visual assessment of damage, the results of this study can also provide scientific data for further assessment of the damage in economic, social and other areas.

At the time that this paper was submitted to be published, the Geographical Survey Institute of Japan released an overview diagram (http://www.gsi.go.jp/chirijoho/chirijoho 40022.html) highlighting the serious impact area of tsunami invasion along the coast that was obtained by the interpretation of aerial images. We find that the invasion range obtained by simulation in this paper is essentially the same as that obtained by aerial image interpretation (Figures 6 and 7). This further validates the reliability of the results and method presented in this paper.
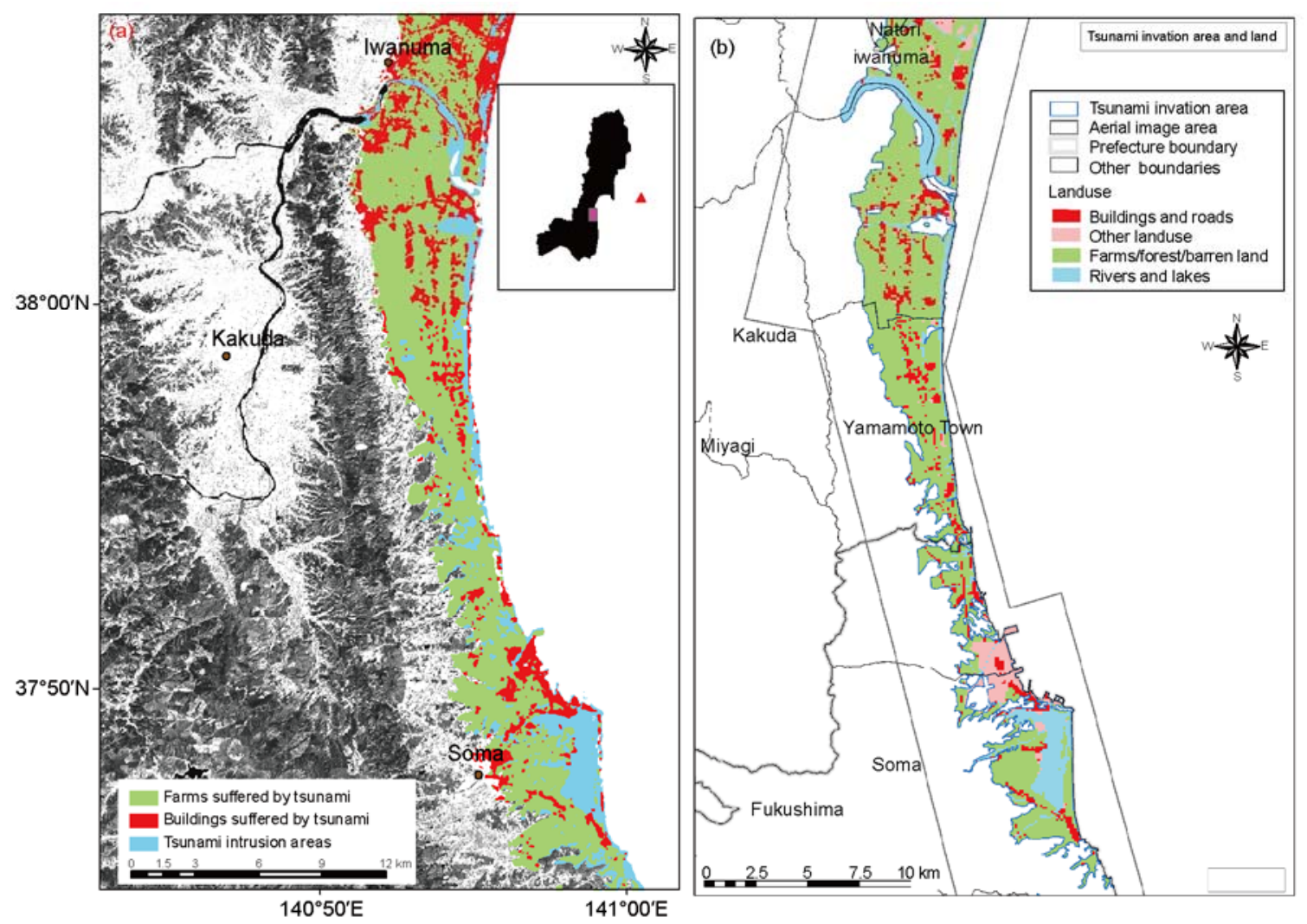

Figure 6 Results obtained by the simulation (a) compared with interpretations made from aerial images (b) ranging from Iwanuma to Soma. Simulated results are essentially the same (just slightly larger) as interpretations of aerial images. 


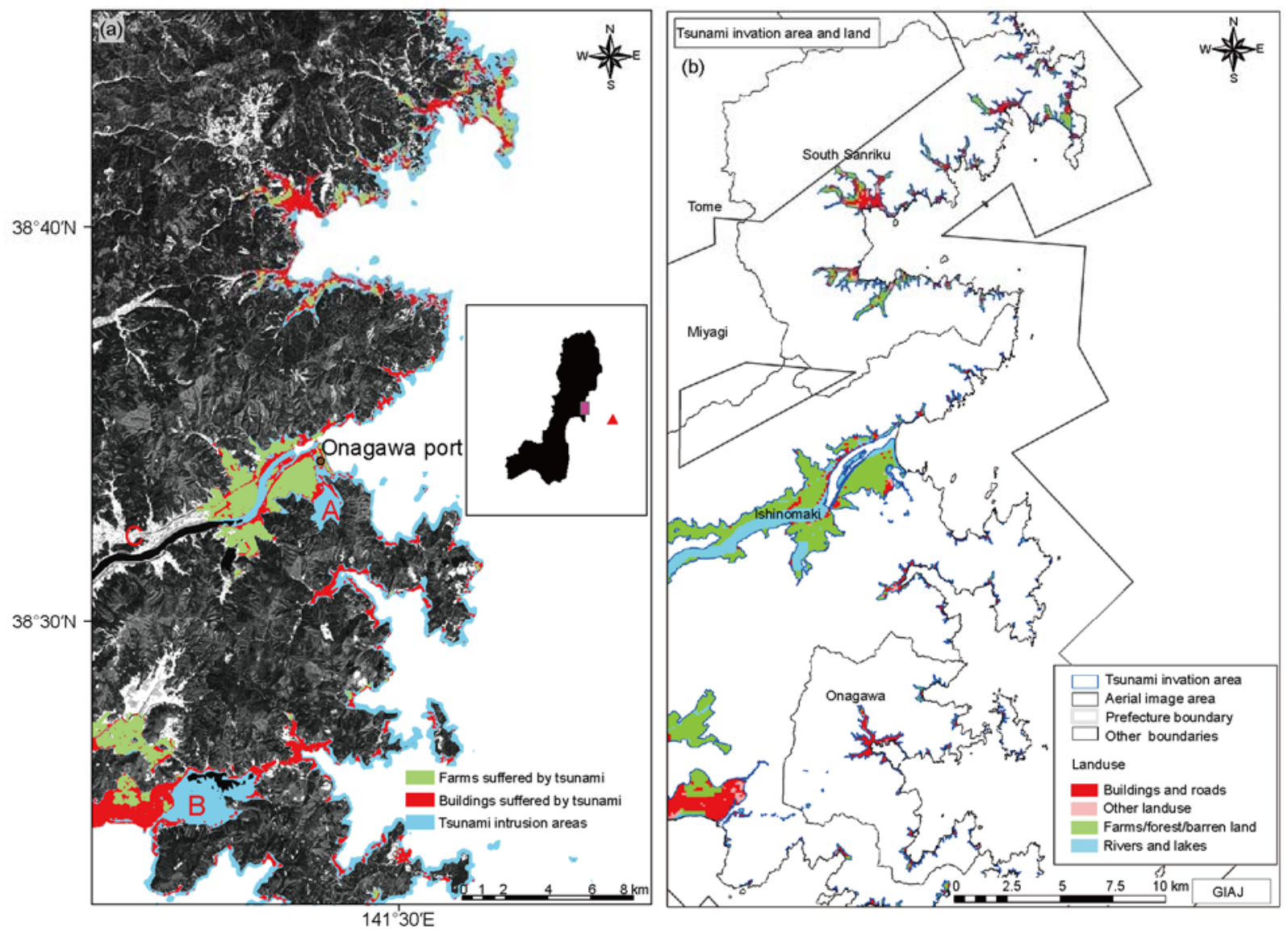

Figure 7 Results obtained by the simulation (a) compared with interpretations of aerial images (b) near the Onagawa port. A and B in (a) were not considered as tsunami intrusion areas by aerial image interpretation because they are almost closed lakes. $\mathrm{C}$ which was affected by tsunami effects in upstream rivers is located in the general impact area of the simulation results (Figure 3). Results obtained by the simulation and aerial images are not in conflict.

This work was supported by the National Basic Research Program of China (2009CB723906) and the National Basic Research Development Program of China (2009AA12Z102 and 2009AA12Z147).

1 Chen L Q, Wang L, Yuan L S. Analysis of urban landscape pattern change in Yanzhou city based on TM/ETM+images. Proc Earth
Planet Sci, 2009, 1: 1191-1197

2 Xiao J, Shen Y, Ge J, et al. Evaluating urban expansion and land use change in Shijiazhuang, China, by using GIS and remote sensing. Landscape Urban Plan, 2006, 75: 69-80

3 Jiang D C. The new Japanese seismic intensity representation (in Chinese). Anhui Water Resour Sci Tech, 1999, 1: 63-64

Open Access This article is distributed under the terms of the Creative Commons Attribution License which permits any use, distribution, and reproduction in any medium, provided the original author(s) and source are credited. 